\title{
Ab initio charge analysis of pure and hydrogenated perovskites
}

\author{
Bork, Nicolai Christian; Bonanos, Nikolaos; Rossmeisl, Jan; Vegge, Tejs
}

Published in:

Journal of Applied Physics

Link to article, DOI:

$10.1063 / 1.3536484$

Publication date:

2011

Document Version

Publisher's PDF, also known as Version of record

Link back to DTU Orbit

Citation (APA):

Bork, N. C., Bonanos, N., Rossmeisl, J., \& Vegge, T. (2011). Ab initio charge analysis of pure and hydrogenated perovskites. Journal of Applied Physics, 109(3), 033702. https://doi.org/10.1063/1.3536484

\section{General rights}

Copyright and moral rights for the publications made accessible in the public portal are retained by the authors and/or other copyright owners and it is a condition of accessing publications that users recognise and abide by the legal requirements associated with these rights.

- Users may download and print one copy of any publication from the public portal for the purpose of private study or research.

- You may not further distribute the material or use it for any profit-making activity or commercial gain

- You may freely distribute the URL identifying the publication in the public portal

If you believe that this document breaches copyright please contact us providing details, and we will remove access to the work immediately and investigate your claim. 


\title{
$A b$ initio charge analysis of pure and hydrogenated perovskites
}

\author{
N. Bork, ${ }^{1}$ N. Bonanos, ${ }^{1}$ J. Rossmeisl, ${ }^{2}$ and T. Vegge ${ }^{3, a)}$ \\ ${ }^{1}$ Fuel Cells and Solid State Chemistry Division, Ris $\phi$ National Laboratory for Sustainable Energy, Technical \\ University of Denmark, 4000 Roskilde, Denmark \\ ${ }^{2}$ Department of Physics, Center for Atomic-scale Materials Design, Technical University of Denmark, 2800 \\ Kgs. Lyngby, Denmark \\ ${ }^{3}$ Materials Research Division, Ris $\emptyset$ National Laboratory for Sustainable Energy, Technical University \\ of Denmark, 4000 Roskilde, Denmark
}

(Received 13 August 2010; accepted 4 December 2010; published online 1 February 2011)

\begin{abstract}
We present a density functional theory based Bader analysis of the charge distribution in pure and hydrogenated $\mathrm{SrTiO}_{3}$. We find that the hydrogen defect carries a $+0.56 e$ charge and the $\mathrm{OH}$ defect carries a $+0.50 e$ charge compared to the host oxygen. Calculations on $\mathrm{BaNbO}_{3}, \mathrm{CaTiO}_{3}$, and $\mathrm{SrZrO}_{3}$ support these findings. The distribution of the remaining electronic density decays exponentially with distance to the hydrogen defect. Diffusional paths are calculated wherein the hydrogenic species retain a charge between +0.57 and $+0.54 e$ showing that hydrogen permeation should not be viewed as consisting of virtually independent protonic and electronic transport processes. (C) 2011 American Institute of Physics. [doi:10.1063/1.3536484]
\end{abstract}

\section{INTRODUCTION}

Due to increased interest in hydrogen based technologies, the subject of protons in oxides is currently receiving much attention. The main prospects are usage of solid oxides in energy related technologies, e.g., as hydrogen gas separation membranes ${ }^{1}$ or as electrolytes in solid oxide fuel cells, ${ }^{2}$ where significant savings may be obtained by replacing present technologies based on noble metals and noble metal alloys.

The main hindrance for any application of proton conducting oxides is the low protonic flux of any material investigated so far. ${ }^{3}$ Depending on the material, a low protonic concentration or a low mobility of the protons may be limiting, ${ }^{4}$ but much remains to be understood about the basic mechanisms governing the protonic and electronic transport properties.

It is usually assumed that $\mathrm{H}$ is incorporated in the material through reaction with gaseous $\mathrm{H}_{2}$ or $\mathrm{H}_{2} \mathrm{O},{ }^{5}$ e.g., through

$$
\mathrm{H}_{2} \mathrm{O}(\mathrm{g})+2 \mathrm{O}_{\mathrm{O}}^{x} \rightarrow 2 \mathrm{OH}_{\mathrm{O}}^{\bullet}+2 e^{\prime}+1 / 2 \mathrm{O}_{2}(\mathrm{~g}),
$$

here presented in Kröger-Vink notation; the actual surface reaction may, however, be considerably more complex. ${ }^{6,7}$ Here, the proton is assumed to bind to a lattice oxygen, $\mathrm{O}_{\mathrm{O}}^{x}$, and form a hydroxyl defect, $\mathrm{OH}_{\mathrm{O}}^{*}$, implying full dissociation of proton and electron. The electron, $e^{\prime}$, is believed to transfer to the conduction band or associate with another defect. ${ }^{8,9}$

Hydrogenic defects in oxides are most commonly thought of as protons or hydroxides, but other charges are possible. Hydrides have been suggested, e.g., in mayenite $\left(\mathrm{Ca}_{12} \mathrm{Al}_{14} \mathrm{O}_{33}\right), \mathrm{SiO}_{2}, \mathrm{ZnO}$, and $\mathrm{MgO},{ }^{10-12}$ and recently an apparent hydride conductivity has been measured in several doped and undoped oxides. ${ }^{13-16}$ Even the existence of nascent uncharged $\mathrm{H}$ has been suggested. ${ }^{5,12}$

To assist in resolving this matter, we have performed a density functional theory (DFT) study of the charge distribu-

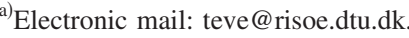

tion and evolution during transport of hydrogen defects. We focus primarily on the $\mathrm{SrTiO}_{3}$ perovskite structure as this material is known to be well described by DFT methods, and proposed to display an apparent hydride ion conductivity, ${ }^{13,15}$ hereby making a more direct comparison of experiment and theory possible.

Determination of atomic charges is ambiguous since this is not an observable property and neither does a quantum mechanical operator for atomic charges exist. Although discussions of atomic charges are arguably arbitrary, this is a deeply rooted concept within physics and chemistry. The usability of atomic charges has routinely been demonstrated, e.g., for predicting materials properties and interpreting experimental results. ${ }^{17}$

Several methods for determining atomic charges are available. For decades the Mulliken charge analysis ${ }^{18}$ has been widely used, since the Mulliken charges are readily available from orbital based $a b$ initio calculations. The Mulliken charge partitioning method, however, has significant disadvantages arising from a weak theoretical basis. Further, the Mulliken method has problems with basis set consistency and occasional $<0$ and $>2$ orbital occupancy. Recently, the Bader charge partitioning method ${ }^{19}$ has become the method of choice. The system is thereby divided into atomic volumes by surfaces which are minima with respect to the electronic density. Besides a few special exceptions, ${ }^{20,21}$ the electronic density peaks at the atomic nuclei and every atom is therefore assigned exactly one volume.

Three significant advantages of the Bader method are noted. (i) The method has a firm theoretical basis. Properties of the atoms are obtained by integration of the proper operator within the atomic volume and the sum of the atomic properties yields the total molecular/system property. $^{22}$ (ii) The partitioning of the system is unbiased with respect to method of obtaining the electronic density. (iii) The elec- 
TABLE I. Average atomic Bader charges on perfect and hydrogenated $\mathrm{SrTiO}_{3}$ (a.u.).

\begin{tabular}{lccccc}
\hline \hline Supercell & Formula & $\mathrm{Sr}$ & $\mathrm{Ti}$ & $\mathrm{O}$ & $\mathrm{H}$ \\
\hline $2 \times 2 \times 2$ & $\left(\mathrm{SrTiO}_{3}\right)_{8}$ & $1.59(7)$ & $1.92(7)$ & $-1.17(5)$ & $\ldots$ \\
& $\left(\mathrm{SrTiO}_{3}\right)_{8} \mathrm{H}$ & $1.58(9)$ & $1.90(7)$ & $-1.18(9)$ & $0.55(8)$ \\
$3 \times 3 \times 3$ & $\left(\mathrm{SrTiO}_{3}\right)_{27}$ & $1.59(6)$ & $1.91(7)$ & $-1.17(1)$ & $\ldots$ \\
& $\left(\mathrm{SrTiO}_{3}\right)_{27} \mathrm{H}$ & $1.59(4)$ & $1.91(6)$ & $-1.17(7)$ & $0.55(8)$ \\
\hline \hline
\end{tabular}

tronic density is an observable and results may be experimentally verified, e.g., using x-rays. See also Bachrach ${ }^{23}$ for an extensive review.

\section{COMPUTATIONAL DETAILS}

The electronic structure calculations were performed using the VASP package and the projector augmented wave method (PAW) ${ }^{24,25}$ with kinetic energy cutoff for the plane waves set to $400 \mathrm{eV}$. The majority of the calculations were performed using the generalized gradient approximation exchange-correlation functional by Perdew, Burke, and Ernzerhof (PBE) ${ }^{26}$ PBE-based functionals have been found to describe most properties of $\mathrm{SrTiO}_{3}$ well, ${ }^{27}$ except for the band gap, which is underestimated by approximately $1 \mathrm{eV}$. Here, the computationally more expensive nonlocal LDA $+\mathrm{U}$ calculations ${ }^{28}$ are also performed in order to assess potential charge delocalization effects which might affect the Bader charges. Recently, Zhu et al. ${ }^{29}$ have demonstrated the strength of the combination of DFT, DFT $+\mathrm{U}$ and the Bader method in a related system. Setting $\mathrm{U}_{e f f}=8.5 \mathrm{eV}$ yields a 3.2 $\mathrm{eV}$ band $\mathrm{gap}^{30,31}$ in agreement with experiment, ${ }^{32}$ but the results were not found to be sensitive to the value of $\mathrm{U}_{\text {eff }}$. Where LDA $+\mathrm{U}$ has been applied, it is explicitly stated.

Only the gamma point was sampled in the $3 \times 3 \times 3$ supercells (135 atoms) while a $2 \times 2 \times 2$ Monkhorst-Pack k-point grid $^{33}$ was used for the $2 \times 2 \times 2$ supercells (40 atoms). For structural optimizations, a $10^{-5} \mathrm{eV}$ electronic convergence criterion and $10^{-4} \mathrm{eV} / \AA$ ionic force convergence criterion have been applied.

The Bader charge analysis was performed with electronic cutoffs increased to $10^{-7} \mathrm{eV}$, on already optimized structures. The wave functions were expanded on a 300 $\times 300 \times 300$ grid and the localized charges on a $450 \times 450$ $\times 450$ grid. The algorithm by Henkelman et al. was used for the actual charge partitioning. ${ }^{20,34,35}$

Reaction paths for the partially delocalized defects ${ }^{36}$ were determined using the climbing image-nudged elastic band (NEB) method. ${ }^{37-39}$

\section{RESULTS AND DISCUSSION}

The PBE determined unit cell lattice constant was determined to be $3.926 \AA$ in good agreement with the $3.905 \AA$ obtained experimentally. ${ }^{40}$

Using PBE, the Bader charges were hereafter calculated for both $2 \times 2 \times 2$ and $3 \times 3 \times 3$ supercells to determine the sensitivity towards varying computational parameters $(\mathrm{k}$ points and grid). See Table I. Even though small changes are apparent, the consistency is satisfactory, implying that the results in either system will be descriptive of the other. We conclude that the atomic charges in cubic $\mathrm{SrTiO}_{3}$ are best describes as $\mathrm{Sr}^{1.60}, \mathrm{Ti}^{1.92}$, and $\mathrm{O}^{-1.17}$; $\mathrm{LDA}+\mathrm{U}$ calculations yielded charges to within a few percent.

A neutral hydrogen atom was hereafter introduced into both the $2 \times 2 \times 2$ and $3 \times 3 \times 3$ supercells. The most stable $\mathrm{H}$ site was characterized by an $\mathrm{OH}$ bond of $0.988 \AA$, symmetrically located between the $\mathrm{Sr}$ anions. This is generally accepted as the most stable site in simple perovskites. ${ }^{3,41}$ The large unit cell is more in accordance with a real crystal due to the expected low $\mathrm{H}$ concentration, ${ }^{4}$ but NEB calculations become too expensive in this size cell. It has however been demonstrated that the errors in performing NEB in the 2 $\times 2 \times 2$ supercell are small for $\mathrm{SrTiO}_{3} .{ }^{42}$

The average charges are listed in Table I. We see that the $\mathrm{H}$ is carrying an approximate charge of $+0.56 e$ regardless of being in a small or large unit cell, confirming that the charges determined in one system is descriptive of the other. Inserting a proton only (and a compensating homogeneous negative background charge), instead of both proton and electron, did not change the charges significantly $(<1.5 \%)$. This is in accordance with the findings of Xiong and Robertson ${ }^{43}$ and the LDA $+\mathrm{U}$ calculations only differed negligibly.

To clarify whether the $+0.56 e$ charge on the hydrogen atom in $\mathrm{SrTiO}_{3}$ is a typical value in perovskite systems, three other perovskites were investigated. $\mathrm{BaNbO}_{3}, \mathrm{CaTiO}_{3}$, and $\mathrm{SrZrO}_{3}$ were chosen since they frequently are mentioned as candidates for proton or hydrogen conducting membranes. ${ }^{44-46} 2 \times 2 \times 2$ supercells were considered based on experimentally obtained unit cells and geometries. ${ }^{47-49}$ The Bader charges were determined and the resulting hydrogen charges are displayed in Table II. Considering also the $\mathrm{OH}$ containing molecules it is clear that the charge on $\mathrm{H}$ is primarily determined by the bond to the oxygen and much less by the other atoms in the material and that the typical $\mathrm{H}$ charge is $+0.54-0.60 e$.

It is clear that upon incorporation of $1 / 2 \mathrm{H}_{2}$ into the $\mathrm{SrTiO}_{3}$ crystal, a full electron must be accounted for. Since $\mathrm{H}$ in itself only accounts for $44 \%$ of the electron density, the rest must be associated with other atoms. The oxygen bound to the hydrogen is the main carrier of the missing charge. The charge of this oxygen is increased from -1.17 to

TABLE II. Bader charges on $\mathrm{H}$ in $\mathrm{OH}$ in various materials (a.u.). $\dagger$ denotes data from this study.

\begin{tabular}{lcccc}
\hline \hline Material & $\mathrm{SrTiO}_{3}$ & $\mathrm{BaNbO}_{3}$ & $\mathrm{CaTiO}_{3}$ & $\mathrm{SrZrO}_{3}$ \\
Charge on $\mathrm{H}$ & $0.56^{\dagger}$ & $0.54^{\dagger}$ & $0.57^{\dagger}$ & $0.60^{\dagger}$ \\
Material & $\mathrm{H}_{2} \mathrm{O}$ & $\mathrm{H}_{2} \mathrm{O}_{2}$ & $\mathrm{HCOOH}$ & $\mathrm{CH}_{3} \mathrm{COOH}$ \\
Charge on $\mathrm{H}$ & $0.567^{\mathrm{a}}$ & $0.547^{\mathrm{b}}$ & $0.580^{\mathrm{c}}$ & $0.579^{\mathrm{c}}$ \\
\hline \hline
\end{tabular}

${ }^{\mathrm{a}}$ Reference 20

${ }^{\mathrm{b}}$ Reference 34.

${ }^{\mathrm{c}}$ Reference 50. 


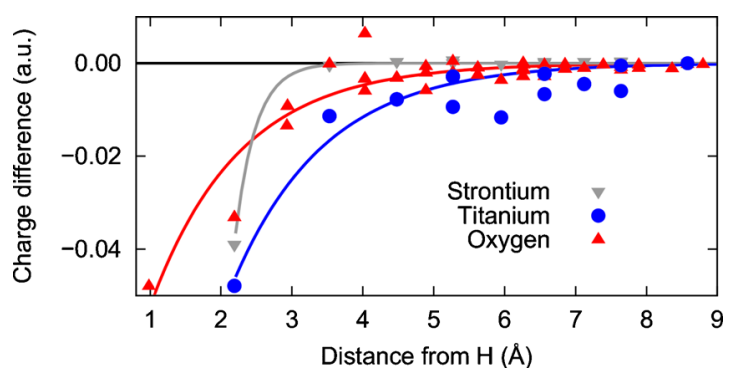

FIG. 1. (Color online) Change in charge on $\mathrm{Sr}, \mathrm{Ti}$, and $\mathrm{O}$ atoms from perfect to singly hydrogenated but otherwise undistorted cubic $3 \times 3 \times 3 \quad \mathrm{SrTiO}_{3}$. Lines are fitted exponentials. Same trends are apparent in the relaxed system, but with larger scattering.

$-1.23 e$. The hydroxyl species is thus formally written $\mathrm{OH}_{\mathrm{O}}^{0.50^{\bullet}}$ and the formation of the defect occur through

$$
\mathrm{H}_{2} \mathrm{O}(\mathrm{g})+2 \mathrm{O}_{\mathrm{O}}^{x} \rightarrow 2 \mathrm{OH}_{\mathrm{O}}^{0.50 \bullet}+e^{-}+1 / 2 \mathrm{O}_{2}(\mathrm{~g}) .
$$

Comparing this to reaction (1) we see that the main difference is in the charge balance.

Searching for the remaining electronic density, a general increase with decreasing distance to the hydrogen was noticeable, but large variations were found as a consequence of lattice deformation shielding or exposing a given atom to the proton and hence extra charge. These effects are real and will be present in a real material, but in order to illuminate further on the distribution of the remaining charge, we performed similar calculations without relaxing the lattice upon insertion of the $\mathrm{H}$ atom. The Bader charge analysis on this undistorted cubic system showed that the increased electronic charge decays exponentially with distance to $\mathrm{H}$ as illustrated in Fig. 1. Not until approximately $8 \AA$ have all charges converged.

We conclude that half of the electronic charge induced by the hydrogen is directly associated with the hydroxyl defect. The remaining electronic density is not evenly smeared, but decrease with distance to the $\mathrm{H}$ defect. The decrease can be viewed as an exponential decay from the hydrogen perturbed by a lattice distortion. While only the two closest $\mathrm{Sr}$ atoms are noticeably affected by the extra charge, the Ti and $\mathrm{O}$ atoms are affected at distances up to approximately $8 \AA$.

It is generally assumed that the proton diffuses via the Grotthuss mechanism wherein proton diffusion consist of $\mathrm{H}$ jumps and $\mathrm{OH}$ reorientations. ${ }^{51,52}$ These were both investigated using the NEB algorithm (see Fig. 2). The barriers were found to be consistent with previous studies at $0.16 \mathrm{eV}$ and $0.28 \mathrm{eV}$ for the rotation and jump, respectively. ${ }^{4} \mathrm{~A}$

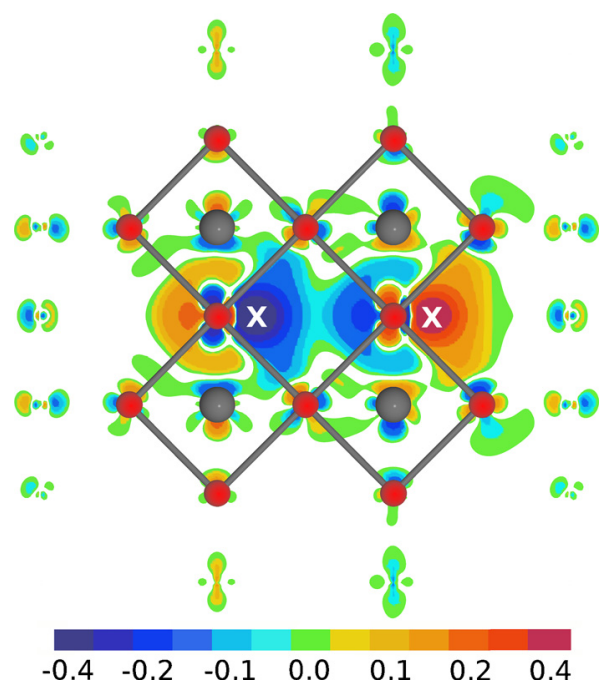

FIG. 3. (Color online) Change in electronic density from a proton diffusing one perovskite unit cell (left to right) through a rigid lattice in a $3 \times 3 \times 3$ supercell. The proton positions are indicated by "X." The nearest oxygen atoms (red spheres) and titanium atoms (gray spheres) are indicated. Units are in $e / \AA^{3}$.

charge analysis was hereafter conducted on all intermediate configurations to follow the charge distribution during diffusion.

The 0.56 equilibrium charge is, at the transition states only reduced to approximately 0.54 regardless of the mechanism, i.e., the $\mathrm{H}$ charge is virtually constant, even during jumps between different oxygen atoms. During an $\mathrm{OH}$ rotation, the charge dependence is smooth, while the charge dependence during $\mathrm{H}$ jumps is more abrupt. This is caused by geometrical changes during the reactions. While the $\mathrm{OH}$ distance slowly decreases until the transition state is reached during a rotation, the shortest $\mathrm{OH}$ distance of the jump increases more abruptly exactly when the $\mathrm{H}$ is being transferred from one $\mathrm{O}$ to another. From these results it is evident that the hydrogen defect remains partially charged during the dynamical transport processes. $\mathrm{LDA}+\mathrm{U}$ calculations were also performed on the transition states, but did not yield significantly different results for the charge localization.

Figure 3 shows the change in electronic density imposed by a proton diffusing one perovskite unit cell length, corresponding to two $\mathrm{OH}$ rotations and two $\mathrm{H}$ jumps, in a $3 \times 3$ $\times 3$ supercell. For clarity, the lattice has been kept fixed. As the proton moves from left to right it is clear that electronic density disappear at the former protonic site and appear at the new protonic site. It is also obvious that the changes in electron density on the remaining atoms strongly depend on

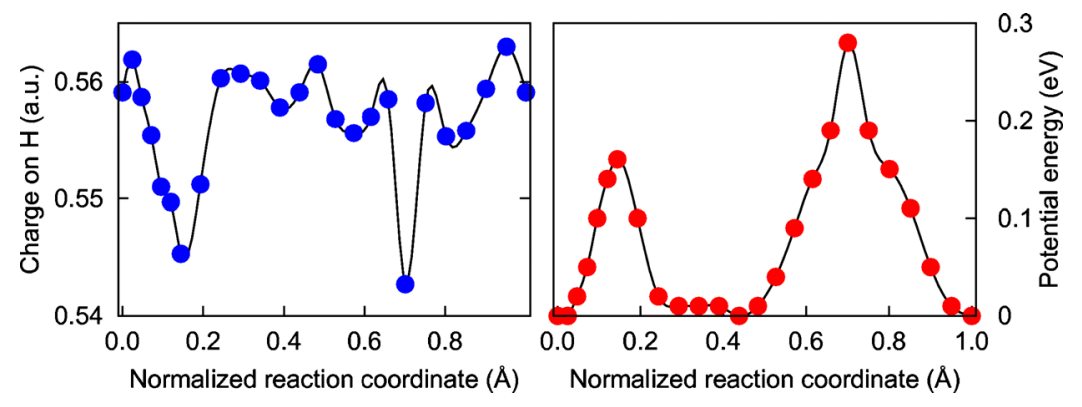

FIG. 2. (Color online) Charge and energy profile of diffusing hydrogen in $\mathrm{SrTiO}_{3}$. Diffusion is modeled as an $\mathrm{OH}$ rotation followed by a $\mathrm{H}$ jump. 
the distance to the $\mathrm{H}$ atom. This is consistent with the results from Fig. 1. Combined with Fig. 2 this signifies that the "protonic" transport effectively carries a near neutral, but partially delocalized charge. The electronic and protonic conductivities should therefore not be considered as separate properties.

\section{CONCLUSIONS}

We have investigated hydrogen charges in $\mathrm{SrTiO}_{3}$ using the Bader charge analysis method based on DFT electronic structure calculations. We determine the hydrogen charge to approximately $0.56 e$, but best described as $\mathrm{OH}_{\mathrm{O}}^{0.50 \bullet}$ due to increased charge on the host oxygen atom. These $\mathrm{H}$ charges are in agreement with results from other perovskites and in molecular systems, and we conclude that the $\mathrm{OH}$ bond is the main descriptor for $\mathrm{H}$ charge. Only small differences were found when comparing PBE and LDA+U calculations.

The remaining electronic charge is not evenly smeared on the surrounding atoms, but distributed mainly on the oxygen and titanium and decaying exponentially from the hydrogen. Variations caused by lattice deformation are however significant.

The diffusional paths of a Grotthuss diffusional mechanism have been determined and the charge development during the diffusion has been investigated. We find the charge decreasing approximately $0.015 e(2 \%-3 \%)$ at the transition states for both $\mathrm{H}$ jumps and $\mathrm{OH}$ reorientations. We conclude that hydrogen permeation in this model perovskite should not be viewed simply as decoupled protonic and electronic conductivities, since the hydrogen defect carries a semilocalized net charge close to neutral.

\section{ACKNOWLEDGMENTS}

This work have been funded by Risø DTU as part of the "Initiative for Hydrogen Separation Membranes." The authors would like to acknowledge the Danish Center for Scientific Computing and the Nordic Center of Excellence on Hydrogen Storage Materials. The Center for Atomic Scale Material Design is supported by the Lundbeck foundation and the Catalysis for Sustainable Energy initiative is funded by the Danish Ministry of Science, Technology and Innovation.

${ }^{1}$ S. C. A. Kluiters, Energy Center of the Netherlands (Petten, The Netherlands, 2004).

${ }^{2}$ K. D. Kreuer, S. J. Paddison, E. Spohr, and M. Schuster, Chem. Rev. 104, 4637 (2004).

${ }^{3}$ K. D. Kreuer, Annu. Rev. Mater. Res. 33, 333 (2003).

${ }^{4}$ N. Bork, N. Bonanos, J. Rossmeisl, and T. Vegge, Phys. Rev. B 82 , 014103 (2010)

${ }^{5}$ T. Norby, M. Viderøe, R. Glöckner, and Y. Larring, Dalton Trans. 19, 3012 (2004).

${ }^{6}$ J.-H. Yu, J.-S. Lee, and J. Maier, Solid State Ionics 181(3-4), 154 (2010).

${ }^{7}$ J. A. Enterkin, A. K. Subramanian, B. C. Russell, M. R. Castell, K. R. Poeppelmeier, and L. D. Marks, Nature Mater. 9, 245 (2010).

${ }^{8}$ P. G. Sundell, M. E. Björketun, and G. Wahnström, Phys. Rev. B 73,
104112 (2006).

${ }^{9}$ M. E. Björketun, P. G. Sundell, and G. Wahnström, Faraday Discuss. 134, 247 (2007).

${ }^{10}$ K. Hayashi, M. Hirano, and H. Hosono, Bull. Chem. Soc. Jpn. 80(5), 872 (2007).

${ }^{11}$ A. Yokozawa and Y. Miyamoto, Phys. Rev. B 55, 13783 (1997).

${ }^{12}$ C. G. Van de Walle, J. Alloys Compd. 446-447, 48 (2007).

${ }^{13}$ M. Widerøe, N. Kochetova, and T. Norby, Dalton Trans. 19, 3147 (2004).

${ }^{14}$ M. Widerøe, R. Waser, and T. Norby, Solid State Ionics 177, 1469 (2006).

${ }^{15}$ S. Steinsvik, Y. Larring, and T. Norby, Solid State Ionics 143, 103 (2001).

${ }^{16}$ T. Norby and Y. Larring, Solid State Ionics 136-137, 139 (2000).

${ }^{17}$ P. Kofstad and T. Norby, Defects and Transport in Crystalline Solids (University of Oslo, Oslo, 2007).

${ }^{18}$ R. S. Mulliken, J. Chem. Phys. 23, 1833 (1955).

${ }^{19}$ R. F. W. Bader, Can. J. Chem. 76(7), 1082 (1998).

${ }^{20}$ G. Henkelman, A. Arnaldsson, and H. Jónsson, Comput. Mater. Sci. 36, 354 (2006)

${ }^{21}$ K. E. Edgecombe, R. O. Esquivel, and V. H. Smith, Jr., J. Chem. Phys. 97, 2593 (1992).

${ }^{22}$ R. F. W. Bader, Atoms in Molecules-A Quantum Theory (Oxford University Press, Oxford, 1990), p. 7.

${ }^{23} \mathrm{~S}$. M. Bachrach, in Reviews in Computational Chemistry, edited by K. B. Lipkowitz and D. B. Boyd (VCH, Weinheim, 1994).

${ }^{24}$ P. E. Blöchl, Phys. Rev. B 50, 17953 (1994).

${ }^{25}$ G. Kresse and D. Joubert, Phys. Rev. B 59, 1758 (1999).

${ }^{26}$ J. P. Perdew, K. Burke, and M. Ernzerhof, Phys. Rev. Lett. 77, 3865 (1996).

${ }^{27}$ R. Wahl, D. Vogtenhuber, and G. Kresse, Phys. Rev. B 78, 104116 (2008).

${ }^{28}$ S. L. Dudarev, G. A. Botton, S. Y. Savrasov, C. J. Humphreys, and A. P. Sutton, Phys. Rev. B 57, 1505 (1998).

${ }^{29}$ L. Zhu, L. Li, T. Cheng, and G. Wei, Phys. Status Solidi B 247, 1521 (2010).

${ }^{30}$ J. Lee and A. A. Demkov, Phys. Rev. B 78, 193104 (2008).

${ }^{31}$ C. H. Park, J. Korean Phys. Soc. 56, 490 (2010).

${ }^{32}$ K. van Benthem, C. Elsasser, and R. H. French, J. Appl. Phys. 90, 6156 (2001).

${ }^{33}$ H. J. Monkhorst and J. D. Pack, Phys. Rev. B 13, 5188 (1976).

${ }^{34}$ E. Sanville, S. D. Kenny, R. Smith, and G. Henkelman, J. Comput. Chem. 28, 899 (2007).

${ }^{35}$ W. Tang, E. Sanville, and G. Henkelman, J. Phys.: Condens. Matter 21, 084204 (2009).

${ }^{36}$ T. Vegge and K. W. Jacobsen, J. Phys.: Condens. Matter 14, 2929 (2002).

${ }^{37}$ G. Mills, H. Jónsson, and G. Schenter, Surf. Sci. 324, 305 (1995).

${ }^{38}$ H. Jónsson, G. Mills, and K. W. Jacobsen, Nudged Elastic Band Method for Finding Minimum Energy Paths of Transitions, in Classical and Quantum Dynamics in Condensed Phase Simulations, B. J. Berne, G. Ciccotti, and D. F. Coker, Eds. (World Scientific, Singapore, 1998), p. 385.

${ }^{39}$ G. Henkelman, B. P. Uberuaga, and H. Jónsson, J. Chem. Phys. 113, 9901 (2000).

${ }^{40}$ T. Yamanaka, N. Hirai, and Y. Komatsu, Amer. Mineral. 87(8-9), 1183 (2002).

${ }^{41}$ C. H. Park and D. J. Chadi, Phys. Rev. Lett. 84, 4717 (2000).

${ }^{42}$ N. Bork, N. Bonanos, J. Rossmeisl, and T. Vegge (unpublished).

${ }^{43}$ K. Xiong and J. Robertson, App. Phys. Lett. 85, 2577 (2004).

${ }^{44}$ X. Yu, Y. Li, and K. Kalantar-Zadeh, Sens. Actuators B 136, 1 (2009).

${ }^{45}$ W. Münch, K. D. Kreuer, G. Seifert, and J. Majer, Solid State Ionics 125, 39 (1999).

${ }^{46}$ K. D. Kreuer, S. Adams, W. Münch, A. Fuchs, U. Klock, and J. Maier, Solid State Ionics 145, 295 (2001).

${ }^{47}$ Y. Grin, H. Mueller-Buschbaum, and H. G. Von Schnering, Z. Naturforsch. B 52, 153 (1997).

${ }^{48}$ M. Ahtee, A. M. Glazer, and A. W. Hewat, Acta Crystallogr. B 34(3), 752 (1978).

${ }^{49}$ T. Barth, Nor. Geol. Tidsskr. 8, 201 (1925).

${ }^{50}$ F. De Proft, C. Van Alsenoy, A. Peeters, W. Langenaeker, and P. Geerlings, J. Comput. Chem. 23, 1198 (2002).

${ }^{51}$ T. Norby and P. Kofstad, Solid State Ionics 20, 169 (1986).

${ }^{52}$ K. D. Kreuer, Chem. Mater. 8, 610 (1996). 